\title{
Endoscopic lumbar disc surgery: The hammer and the nail problem or the "Not-So-Easy Go" system
}

\author{
Bernhard Meyer
}

Published online: 24 July 2009

(C) Springer-Verlag 2009

The saying goes: "if you have a hammer, everything looks like a nail".

This holds true for the communication by Oertel et al. [1], despite the honesty they display in it for which they are to be commended.

I am grateful for the opportunity to write an editoral, because it may help to clarify some issues:

Although there is no proof at all that minimally invasive access translates into a clinically meaningful advantage[2], the perpetual quest for it is understandable and certainly justified. It is my firm conviction that papers dealing with this topic are necessary, because progress in science as well as advances in surgery will always come in very small steps these days.

Thus, refuting new techniques or modifications completely for the above reason is not my concept at all. However, two prerequisites need to be met when a new technique is promoted:

1. It should truly represent a visible advantage over existing techniques with respect to minimal invasiveness.

2. At least equivalence to standard results is required.

For the technique described here, the first goal has certainly not been achieved, and whether the second is remains doubtful at least.

B. Meyer $(\bowtie)$

Department of Neurosurgery, Technical University of Munich,

Klinikum rechts der Isar, Ismaninger Str. 22,

81675 Munich, Germany

e-mail: Bernhard.meyer@1rz.tum.de
Why is this so?

This paper promotes endoscopy-assisted lumbar disc surgery as opposed to the full endoscopic technique. The latter fulfills the first requirement and has a visible advantage with respect to invasiveness over microscopic techniques. Whether there is equivalence of results lies in the eyes of the beholder (i.e, [3, 4].) For me, there are more studies pointing to slightly inferior results plus a prolonged OR time and a long learning curve.

In the authors' line of arguments, the full endoscopic technique has the drawback that it requires operative skills different from the ones the microscopically trained neurosurgeon has acquired. Therefore, they designed a system that allows the surgeon to work in his accustomed microsurgical way with the corresponding instruments. Minimally invasive access was achieved with a standard muscular dilator system and a work sheath with a $1.5-\mathrm{cm}$ outer diameter.

So far, there is not much disagreement.

However, the misconcept of the authors lies in the fact that a tube with an outer diameter of $1.5 \mathrm{~cm}$ is thought to be too small for a microscopic view. This is simply not true. They are obviously not aware that tubular systems have been around for many years and are in widespread use for microscopic lumbar discectomy (i.e., [5]). Lumbar disc surgery can be performed through 14-mm outer-diameter tubes without problems by many people I know using the corresponding instruments plus having the advantage of the view they are acquainted with, which is for most neurosurgeons still the one through the microscope and not the endoscope. 
This is the authors' major leap in logic, which most likely occurred because they are dedicated endoscopic neurosurgeons (the hammer and nail problem!).

Despite the fact that they are more familiar with endoscopes than the average neurosurgeon, it took them longer ( $20 \%$ when compared to their historical microsurgical control) without the prospect to reduce this with a prolonged learning curve. The results were comparable apart from a slightly higher recurrence rate.

So until they prove the opposite, it seems that this is rather the "Not-So-Easy Go" system.

To play the devil's advocate futher, I assume that this is in part because manipulations are rendered unnecessarily difficult. (1) Some of the workspace is obstructed by the endoscope, and (2) the work sheath is way too long, sticking out high above the skin level instead of being flush with it as it should.

\section{References}

1. Oertel JK, Mondorf Y, Gaab MR: A new endoscopic spine system: First results with the EASY GO system. Acta Neurochir (Wien) $\operatorname{xxxxxx}$

2. Gibson JN, Waddell G (2007) Surgical interventions for lumbar disc prolapse. Cochrane Database Syst Rev. Apr 18;(2):CD001350. Review

3. Ruetten S, Komp M, Merk H, Godolias G (2008) Full-endoscopic interlaminar and transforaminal lumbar discectomy versus conventional microsurgical technique: a prospective, randomized, controlled study. Spine 33(9):931-939

4. Righesso O, Falavigna A, Avanzi O (2007) Comparison of open discectomy with microendoscopic discectomy in lumbar disc herniations: results of a randomized controlled trial. Neurosurgery 61(3):545-549

5. Ryang YM, Oertel MF, Mayfrank L, Gilsbach JM, Rohde V (2008) Standard open microdiscectomy versus minimal access trocar microdiscectomy: results of a prospective randomized study. Neurosurgery 62(1):174-181 